\title{
Obesogenic neighbourhoods: the impact of neighbourhood restaurants and convenience stores on adolescents' food consumption behaviours
}

\author{
Meizi He ${ }^{1, *}$, Patricia Tucker ${ }^{2}$, Jennifer D Irwin ${ }^{3}$, Jason Gilliland ${ }^{4}$, Kristian Larsen ${ }^{5}$ \\ and Paul Hess 5 \\ 'Department of Health \& Kinesiology, The University of Texas at San Antonio, One UTSA Circle, San Antonio, \\ TX 78249, USA: ${ }^{2}$ School of Occupational Therapy, Elborn College, University of Western Ontario, London, ON, \\ Canada: ${ }^{3}$ School of Health Studies, Faculty of Health Sciences, University of Western Ontario, London, ON, \\ Canada: ${ }^{4}$ Department of Geography, University of Western Ontario, London, ON, Canada: ${ }^{5}$ Department of \\ Geography and Program in Planning, University of Toronto, Toronto, ON, Canada
}

Submitted 3 April 2010: Accepted 26 January 2012: First published online 6 March 2012

\begin{abstract}
Objective: To examine the relationship between the neighbourhood food environment and dietary intake among adolescents.

Design: Cross-sectional design using: (i) a geographic information system to assess characteristics of the neighbourhood food environment and neighbourhood socioeconomic status; (ii) the modified Healthy Eating Index (HEI) to assess participants' overall diet quality; and (iii) generalized linear models to examine associations between HEI and home and school food environmental correlates.

Setting: Mid-sized Canadian city in Ontario, Canada.

Participants: Grade 7 and 8 students ( $n$ 810) at twenty-one elementary schools.

Results: Students living in neighbourhoods with a lower diversity of land-use types, compared with their higher diversity counterparts, had higher HEI scores $(P<0 \cdot 05)$. Students with more than $1 \mathrm{~km}$ between their home and the nearest convenience store had higher HEI scores than those living within $1 \mathrm{~km}(P<0 \cdot 01)$. Students attending schools with a distance further than $1 \mathrm{~km}$ from the nearest convenience store $(P<0 \cdot 01)$ and fast-food outlet $(P<0 \cdot 05)$ had higher HEI scores than those within $1 \mathrm{~km}$. Those attending schools with three or more fast-food outlets within $1 \mathrm{~km}$ had lower HEI scores than those attending schools with no fast-food outlet in the school surroundings $(P<0 \cdot 05)$.

Conclusions: Close proximity to convenience stores in adolescents' home environments is associated with low HEI scores. Within adolescents' school environments, close proximity to convenience and fast-food outlets and a high density of fast-food outlets are associated with low HEI scores.
\end{abstract}

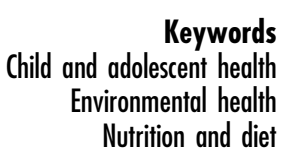

Obesity among all age groups has become a national and international public health concern ${ }^{(1)}$ associated with numerous and well-established negative health consequences $^{(2)}$. Given the propensity for obesity throughout youth to extend into adulthood, focusing on the younger years is particularly important ${ }^{(3)}$. Similar to what is happening in many other places in the world, in Canada more than a quarter of children and adolescents are overweight or obese ${ }^{(4,5)}$, and therefore successful prevention efforts are warranted. A number of interventions targeting obesity-related behaviours (i.e. physical activity and diet) have been undertaken, but most have targeted individual behaviours only, in a single setting and addressing only an individual risk factor for chronic disease $^{(6)}$. Because physical activity and diet, the two modifiable behavioural risk factors for obesity, are influenced by a number of factors, interventions that address environmental influences may be an ideal way to target a large segment of the population and serve as an appropriate public health initiative ${ }^{(6)}$.

The built environment's role in fostering increased energy consumption (through its influence on food availability) and decreased energy expenditure (by facilitating or impeding physical activity) has received increasing attention ${ }^{(7-11)}$; however, this line of research is still in its early stages ${ }^{(12)}$. The built environment has been identified as obesogenic (i.e. encourages obesity) by creating opportunities that support inactivity and foster poor dietary habits ${ }^{(13-15)}$. With regard to dietary behaviours, the availability of fast-food and slow-food restaurants, 
convenience stores and supermarkets has been noted as influential neighbourhood-level characteristics ${ }^{(7,16)}$.

Researchers have identified a disproportionate number of fast-food establishments clustered in low-income, high ethnic minority and more socially deprived neighbourhoods $^{(17,18)}$. Given that adolescents are unable to drive independently, they may be restricted to areas in their home and school neighbourhood(s) to which they can walk or bike. Therefore, youths may be particularly captive to environmental opportunities around their home and school. For instance, in Austin et al.'s recent study in Chicago ${ }^{(19)}$, the authors found a statistically significant clustering of fast-food restaurants within walking distance of schools. Similarly Simon et al. found that a large percentage (65\%) of public schools in Los Angeles have food establishments within walking distance ${ }^{(20)}$. Although the physical presence of these obesogenic opportunities in youths' environments has been fairly well established, one area of research lacking is an assessment of the degree to which fast-food proximity to homes and/or schools influences actual dietary patterns among adolescents ${ }^{(20)}$.

The accusation that the environment has been fostering obesogenic behaviours seems logical given the dramatic increase in food consumption from restaurants and fastfood establishments over the last two decades ${ }^{(21-23)}$. For instance, among American adolescents, the percentage of total energy intake from fast-food and restaurant consumption increased approximately 300\% between 1977 and $1996^{(21,22)}$. Not surprisingly, researchers have found that children who consume fast food have higher intakes of total energy, fat, sugar, carbohydrates and carbonated soft drinks ${ }^{(24)}$. The limited research documenting the impact of convenience stores and fast-food outlets on dietary behaviours of adolescents has revealed a negative association between availability of fast-food and convenience stores and fruit consumption. Specifically, those children with at least one fast-food outlet within $800 \mathrm{~m}$ of their home were $36 \%$ less likely to consume two or more pieces of fruit daily, while those with at least one convenience store in the same buffer around their home were $25 \%$ less likely to eat vegetables three or more times daily than children who did not have these types of stores in their neighbourhood ${ }^{(25)}$.

When considering the potential implications of this location-dietary intake link, researchers have identified a relationship between convenience store density and childhood overweight ${ }^{(26)}$. Powell et al. found that greater availability of chain supermarkets was associated with lower adolescent BMI and overweight, while greater availability of convenience stores was associated with higher BMI and overweight ${ }^{(27)}$. Oreskovic et al. showed that distance to the nearest fast-food restaurant was inversely associated with BMI, whereas density of fast-food restaurants was positively associated with BMI among children aged 2 to 18 years $^{(28)}$. In a recent Canadian study, Spence et al. found lower risks of obesity among individuals who lived in neighbourhoods with fewer fast-food restaurants and convenience stores and higher numbers of grocery stores and produce vendors ${ }^{(29)}$. By contrast, Pearce et al. revealed little evidence to suggest that neighbourhood access to fast-food retailing was associated with poorer diet or overweight ${ }^{(30)}$.

Considering the obesity-related modifiable behaviours (i.e. physical activity and dietary intake), the body of research on nutrition has progressed at a much slower pace than that of physical activity ${ }^{(13)}$. It is essential that we gain a better understanding of the effect of the obesogenic food environment on children's dietary behaviours ${ }^{(12)}$. Neighbourhood-level variables (e.g. accessibility and availability of fast-food restaurants) have the potential to impact a large portion of the population, and community-level policies that affect local food environments have promise to influence dietary behaviours ${ }^{(12)}$.

Although gains have been made in understanding some of the components of the food environment that influence dietary intake and obesity among youth, additional research is warranted to examine the influence of the food environment on Canadian youths' nutrition behaviours. As such, the current study makes an important and unique contribution to the growing body of research by providing the first Canadian data to comprehensively assess the relationship between actual dietary intake and the local foodrelated built environment among youths. The current work was part of a larger study which included documenting environmental influences on food purchasing behaviours and physical activity and walking patterns of grade 7 and 8 students aged 11 to 14 years in London, Ontario, Canada ${ }^{(31-34)}$.

\section{Experimental methods}

The present cross-sectional study was conducted between 2006 and 2007 in London, Ontario, a mid-sized Canadian city of approximately 410000 people ${ }^{(35)}$. The study was approved by the Office of Research Ethics at the University of Western Ontario and the research officers at the two participating school boards. Informed written consent was obtained from both parents and adolescents prior to data collection.

\section{Participants}

Study participants were students in grades 7 and 8 (aged 11-14 years) from a heterogeneous sample of elementary schools varying by income and neighbourhood environment. Of the fifty-one schools invited, twenty-one (41\%) agreed to participate; eleven from the Catholic school system and the remaining ten from the public school board. A total of 1666 students were invited to participate; 810 students received parental consent and were present on the day of data collection representing a response rate of $49 \%$. The complete details of the participants and methodology have been published elsewhere ${ }^{(33)}$. 


\section{Survey instruments and administration}

Children's eating behaviours were measured via an FFQ, the 'Block Kids 2004 FFQ', previously validated for use among youths aged 10 to 17 years ${ }^{(36)}$. This questionnaire comprehensively semi-quantitatively assesses children's diets over the past 12 months. The tool was self-administered in paper format in classrooms with assistance from trained research staff. A short parental questionnaire was sent home to obtain the demographic characteristics of individual households (i.e. household postal code, family income, father's and mother's education and employment). Unique identification numbers were assigned to child-parent pairs prior to the data collection, which allowed for the linkage of data gathered for each child to additional household data gathered through their parent's survey.

\section{Home and school neighbourbood food environmental measures}

A geographic information system (GIS) was used to assess the neighbourhood food environment and socio-economic characteristics. Seven hundred and eighty-two out of the $810(96 \%)$ survey respondents reported a valid home postal code, which was 'geocoded' to the geographic centre of the home postal code using ArcGIS 9.2 (ESRI, Redlands, CA, USA). Postal codes were used instead of exact home addresses to maintain the anonymity of each respondent. On average, there are 10.4 residences per postal code in London. Previous research has suggested that postal codes are a suitable proxy of home neighbourhoods in urban environments $^{(37)}$. Individual home neighbourhoods were defined using a $1 \mathrm{~km}$ 'straight line buffer' (rings of selected radius outlining the home neighbourhood) around the centre point of the postal code of each respondent's home; school neighbourhoods were delineated by creating a $1 \mathrm{~km}$ straight line buffer centred on the main entrance of the school. A $1 \mathrm{~km}$ distance was chosen for the buffer radius as it is commonly used in accessibility studies to represent a 10-15 min walk ${ }^{(38)}$. Data on fast-food outlets, convenience stores and supermarkets were compiled for 2006 using local business directories ${ }^{(38)}$, validated by researchers through telephone calls, field surveys and inspection of aerial photographs, and geocoded to the building's address. Fast-food outlets were defined as restaurants where one orders at a counter and pays in advance for one's food. Convenience stores were classified as small food retailers with a floor area of less than $1000 \mathrm{~m}^{2}$ (e.g. 24-hour variety stores, gas stations selling junk foods), whereas supermarkets were larger food retailers with floor areas greater than $1000 \mathrm{~m}^{2}$. Data on school locations and parcel-level land use were obtained from the City of London Planning Department. These data were used to calculate two types of 'junk food' accessibility measures for each respondent using the Network Analysis functions in GIS: (i) 'junk food density', or the number of fast-food outlets and convenience stores within a $1 \mathrm{~km}$ buffer of the participant's home and school; and (ii) 'junk food proximity', or the shortest distance from the participant's home and school to the nearest fast-food restaurant and convenience store. The shortest distance between the two locations in question was calculated via the shortest possible path along the City of London's circulation network, which included roads, trails and pathways.

\section{Home neighbourbood distress scores}

As neighbourhood disadvantage or 'deprivation' is a multifaceted situation involving additional factors than just low income, we characterized census tracts by a composite index of socio-economic distress comprised of four variables drawn from the 2006 Canadian census: (i) low educational attainment (proportion of adults who have not graduated from high school); (ii) lone parenthood (proportion of families headed by a lone parent $v$. the total number of families); (iii) unemployment (proportion of unemployed adults who are currently available for work); and (iv) incidence of low income (proportion of households that fall below the low income cut-off derived by Statistics Canada). The $Z$-scores (based on unweighted (by census tract population) mean and standard deviation of the indicators) of each neighbourhood were calculated and assigned a value of -1 if the $Z$-score was -1 or less, 1 if the $Z$-score was 1 or more, or 0 otherwise. The assigned value of the four indicators was summed for each neighbourhood to obtain its socio-economic distress index score, which ranged from -4 to +4 . The use of a composite index for statistical modelling, rather than each variable separately, avoids problems of multicollinearity among the variables.

\section{Dietary intake}

All completed Block Kids 2004 FFQ forms were returned to NutritionQuest (Berkeley, CA, USA) for processing. The Block nutrient database was used for nutrient analysis of common food items, with Canadian-specific food items being recalculated based on the updated Csizmadi Canadian DHQ (FFQ) nutrient database in 2007. Data outputs included both nutrient profiles and food group servings based on the MyPyramid food guide ${ }^{(39)}$. A comprehensive index, the modified Healthy Eating Index-2005 (HEI-2005), was calculated to reflect participants' overall diet quality. HEI-2005 is a tool designed to measure diet quality when monitoring population eating behaviours and for determining associations pertaining to diet quality and behavioural, social and environmental correlates in nutrition epidemiology research ${ }^{(40,41)}$. The original HEI-2005 includes twelve dietary components with each reflecting a key aspect of diet quality. All of the components are assessed on an energy density basis (i.e. per $4184 \mathrm{~kJ} / 1000$ kcal) scored separately and then summed to a total score of $100^{(40)}$. Because the current study's dietary data output file contained dietary information for nine out of the twelve components of the original HEI-2005, a modified HEI was calculated with a maximum score of 80 (Table 1). 
Table 1 Modified HEl-2005 components and standards for scoring

\begin{tabular}{|c|c|c|c|}
\hline Component & $\begin{array}{l}\text { Maximum } \\
\text { points }\end{array}$ & Standard for maximum score & $\begin{array}{l}\text { Standard for minimum } \\
\text { score of zero }\end{array}$ \\
\hline Total fruit (includes $100 \%$ juice) & $5 \cdot 0$ & $\geq 0.8$ cup equiv. $/ 4184 \mathrm{~kJ}(1000 \mathrm{kcal})$ & No fruit \\
\hline Total vegetables & $5 \cdot 0$ & $\geq 1 \cdot 1$ cup equiv./4184 kJ (1000 kcal) & No vegetables \\
\hline Total grains & $5 \cdot 0$ & $\geq 3 \cdot 0$ oz equiv./4184 kJ (1000 kcal) & No grains \\
\hline Whole grains & $5 \cdot 0$ & $\geq 1.5$ oz equiv./4184 kJ (1000 kcal) & No whole grains \\
\hline Milk & $10 \cdot 0$ & $\geq 1 \cdot 3$ cup equiv. $/ 4184 \mathrm{~kJ}$ (1000 kcal) & No milk \\
\hline Meat and beans & $10 \cdot 0$ & $\geq 2.5$ oz equiv./4184 kJ (1000 kcal) & No meat or beans \\
\hline Saturated fat & $10 \cdot 0$ & $\leq 7 \%$ of energy & $\geq 15 \%$ of energy \\
\hline Sodium & $10 \cdot 0$ & $\leq 0.7 \mathrm{~g} / 4184 \mathrm{~kJ}(1000 \mathrm{kcal})$ & $\geq 2 \cdot 0 \mathrm{~g} / 4184 \mathrm{~kJ}(1000 \mathrm{kcal})$ \\
\hline Calories from solid fat and added sugar & $20 \cdot 0$ & $\leq 20 \%$ of energy & $\geq 50 \%$ of energy \\
\hline Total score & $80 \cdot 0$ & & \\
\hline
\end{tabular}

HEI-2005, Healthy Eating Index-2005.

One hundred and ninety outliers were excluded based on two criteria: (i) energy intake $<2092 \mathrm{~kJ} / \mathrm{d}(<500 \mathrm{kcal} / \mathrm{d}$; $n$ 20) or $>20920 \mathrm{~kJ} / \mathrm{d}(>5000 \mathrm{kcal} / \mathrm{d} ; n 20)^{(42)}$; and (ii) dietary data with one or more serious error flagged by the NutritionQuest system ( $n$ 130).

\section{Statistical analysis}

Data were entered into the SPSS statistical software package version 18.0 (SPSS Inc., Chicago, IL, USA) for statistical analysis. Missing values were excluded listwise. The level of significance for all statistical tests was set at $0 \cdot 05$.

Environmental variables (i.e. fast-food restaurants, conveniences stores, supermarkets) were categorized into distance from home or school to the nearest fast-food outlet or convenience store as ' $1 \mathrm{~km}$ or closer' and 'further than $1 \mathrm{~km}$ ', as $1 \mathrm{~km}$ was considered within walking distance for adolescents ${ }^{(43)}$. Number of fast-food outlets within a $1 \mathrm{~km}$ buffer of a student's home postal code or school location was used as an index of fast-food outlet density in each adolescent's home neighbourhood and school surroundings.

Given the recruitment strategy used (e.g. children recruited in classrooms), it was necessary to analyse the data as a cluster sample. The SPSS Complex Samples Procedure was used for all descriptive and comparative analyses to account for sampling design effect; this option allows selections of a sample according to a complex design and incorporates the design specifications into the data analysis. Generalized linear models were used to examine the associations between HEI and participants' home neighbourhood food environmental correlates controlling for key demographic factors (i.e. children's grade, gender and neighbourhood distress score tertile). Separate generalized linear mixed models were performed to determine the effect of school surroundings food environmental correlates on participants' HEI scores. The models included HEI as the independent variable, school surroundings environmental indicators as random factors and socio-economic status as covariates. Most environmental variables were correlated - for example, the 'distance to the nearest fast-food outlet' was highly correlated to the 'number of fast-food outlets within a $1 \mathrm{~km}$ buffer' $(r=0 \cdot 88)$. As such, environmental variables were included in the generalized linear models one at a time.
Table 2 Sociodemographic profile of the study participants: grade 7 and 8 students at twenty-one elementary schools, London, Ontario, Canada, 2006-2007

\begin{tabular}{|c|c|c|}
\hline & $n$ & $\%$ \\
\hline \multicolumn{3}{|l|}{ Gender ( $n$ 631) } \\
\hline Boy & 310 & 49 \\
\hline Girl & 321 & 52 \\
\hline \multicolumn{3}{|l|}{ Grade level ( $n$ 632) } \\
\hline 7 & 273 & 43 \\
\hline 8 & 359 & 57 \\
\hline \multicolumn{3}{|l|}{ Age (years) ( $n 744)$} \\
\hline 11 & 11 & 1 \\
\hline 12 & 272 & 34 \\
\hline 13 & 400 & 49 \\
\hline 14 & 61 & 16 \\
\hline \multicolumn{3}{|l|}{ Ethnicity ( $n$ 612) } \\
\hline White & 457 & 75 \\
\hline Latino & 41 & 7 \\
\hline Asians & 29 & 5 \\
\hline Other & 86 & 14 \\
\hline \multicolumn{3}{|l|}{ Father's education ( $n$ 632) } \\
\hline Less than high school & 69 & 11 \\
\hline High school & 171 & 27 \\
\hline College and above & 392 & 62 \\
\hline \multicolumn{3}{|l|}{ Mother's education ( $n$ 611) } \\
\hline Less than high school & 48 & 8 \\
\hline High school & 151 & 25 \\
\hline College and above & 412 & 67 \\
\hline \multicolumn{3}{|l|}{ Family structure ( $n$ 604) } \\
\hline Two-parent home & 493 & 82 \\
\hline Single-parent home & 111 & 18 \\
\hline \multicolumn{3}{|l|}{ Annual family income (\$CAN) ( $n$ 565) } \\
\hline$<30000$ & 49 & 9 \\
\hline $30000-69999$ & 122 & 22 \\
\hline$\geq 70000$ & 183 & 32 \\
\hline \multirow[t]{2}{*}{ Not sure/prefer not to answer } & 211 & 37 \\
\hline & Mean & SD \\
\hline Neighbourhood distress index score $(n 782)$ & -0.211 & $2 \cdot 44$ \\
\hline
\end{tabular}

\section{Results}

In total, 810 students took part in the present study. Among these, 190 were excluded due to implausible dietary data and twelve due to missing home neighbourhood environmental data, thus the final sample in the current study was 632. Students' sociodemographic characteristics are presented in Table 2 . The sample consisted of an even gender 
distribution, but slightly higher portion of 8th compared with 7 th graders (Table 2).

Table 3 presents unadjusted results for food group servings, total energy and its sources, major nutrient intakes, as well as participants' average HEI score.

Table 4 presents HEI scores by students' home neighbourhood food environmental factors. Students whose homes were further than $1 \mathrm{~km}$ from the nearest convenience store had a higher HEI score than those who lived within $1 \mathrm{~km}(P<0 \cdot 05)$.
Table 5 presents HEI scores by food environmental factors within the school surroundings. Students who attended schools that were further than $1 \mathrm{~km}$ from the nearest convenience store $(P<0.05)$ and fast-food outlet $(P<0 \cdot 01)$ had higher HEI scores than those whose schools were within $1 \mathrm{~km}$ of such establishments. Students attending schools with three or more fast-food outlets within $1 \mathrm{~km}$ had lower HEI scores than those with none in the school surroundings $(P<0 \cdot 05)$.

Table 3 Food intakes and nutrient profile of the study participants: grade 7 and 8 students (n 632) at twenty-one elementary schools, London, Ontario, Canada, 2006-2007

\begin{tabular}{|c|c|c|}
\hline Food and nutrient items & Mean & SD \\
\hline \multicolumn{3}{|l|}{ Food groups } \\
\hline Total vegetables, including potatoes $\&$ beans (cups) & $1 \cdot 3$ & $1 \cdot 0$ \\
\hline Total fruits, including juices (cups) & $1 \cdot 7$ & $1 \cdot 2$ \\
\hline Total grains (oz) & $4 \cdot 7$ & $2 \cdot 2$ \\
\hline Whole grains (oz) & 0.9 & 0.7 \\
\hline Diary (cups) & $1 \cdot 9$ & $1 \cdot 0$ \\
\hline Meat, poultry, fish and beans (oz) & $3 \cdot 0$ & 1.9 \\
\hline \multicolumn{3}{|l|}{ Energy } \\
\hline Total energy $(\mathrm{kJ})$ & 7026 & 2713 \\
\hline Percentage of energy from saturated fat & $11 \cdot 6$ & $2 \cdot 2$ \\
\hline Percentage of energy from discretionary calories (solid fat and added sugar) & $43 \cdot 1$ & $9 \cdot 2$ \\
\hline \multicolumn{3}{|l|}{ Selected nutrients } \\
\hline Protein $(\mathrm{g})$ & $60 \cdot 8$ & $25 \cdot 3$ \\
\hline Total fat (g) & $57 \cdot 3$ & $23 \cdot 8$ \\
\hline MUFA (g) & $21 \cdot 1$ & $9 \cdot 4$ \\
\hline PUFA $(\mathrm{g})$ & $10 \cdot 3$ & $4 \cdot 8$ \\
\hline Dietary trans fatty acids $(\mathrm{g})$ & 3.9 & 1.9 \\
\hline Cholesterol (mg) & $182 \cdot 3$ & $103 \cdot 0$ \\
\hline Carbohydrate $(\mathrm{g})$ & $236 \cdot 5$ & $98 \cdot 8$ \\
\hline Added sugar $(\mathrm{g})$ & $84 \cdot 2$ & $4 \cdot 5$ \\
\hline Dietary fibre $(\mathrm{g})$ & $14 \cdot \overline{6}$ & $7 \cdot 3$ \\
\hline $\mathrm{Ca}(\mathrm{mg})$ & $838 \cdot 7$ & $356 \cdot 6$ \\
\hline $\mathrm{Fe}(\mathrm{mg})$ & $11 \cdot 5$ & $4 \cdot 5$ \\
\hline $\mathrm{Na}(\mathrm{mg})$ & $2297 \cdot 1$ & $939 \cdot 9$ \\
\hline \multicolumn{3}{|l|}{ Overall eating } \\
\hline $\mathrm{HEI}(\max =80)$ & $39 \cdot 1$ & $7 \cdot 8$ \\
\hline
\end{tabular}

HEI, modified Healthy Eating Index.

Table 4 HEl scores by home neighbourhood food environmental factors* among grade 7 and 8 students at twenty-one elementary schools, London, Ontario, Canada, 2006-2007

\begin{tabular}{|c|c|c|c|c|}
\hline & $\begin{array}{l}\text { No. of } \\
\text { students }\end{array}$ & $\begin{array}{l}\text { Difference in } \\
\text { HEI scores }\end{array}$ & SE & $P$ \\
\hline \multicolumn{5}{|c|}{ Distance from student's home to the nearest convenience store } \\
\hline$<1 \mathrm{~km}$ & 329 & $0+$ & & \\
\hline$\geq 1 \mathrm{~km}$ & 251 & $1 \cdot 80$ & 0.79 & $0 \cdot 03$ \\
\hline \multicolumn{5}{|c|}{ Distance from student's home to the nearest fast-food outlet } \\
\hline$<1 \mathrm{~km}$ & 303 & $0+$ & & \\
\hline$\geq 1 \mathrm{~km}$ & 277 & $1 \cdot 10$ & 0.65 & 0.08 \\
\hline \multicolumn{5}{|c|}{ Number of fast-food outlet(s) within $1 \mathrm{~km}$ buffer surrounding student's home } \\
\hline 0 & 286 & $0 \cdot 80$ & 0.75 & $0 \cdot 29$ \\
\hline $1-2$ & 147 & -0.95 & $1 \cdot 01$ & $0 \cdot 35$ \\
\hline$\geq 3$ & 147 & $0+$ & & \\
\hline \multicolumn{5}{|c|}{ Distance from student's home to the nearest supermarketł } \\
\hline 1st tertile & 199 & $0+$ & & \\
\hline 2nd tertile & 197 & 0.25 & 0.88 & 0.78 \\
\hline 3rd tertile & 184 & $0 \cdot 16$ & 0.92 & $0 \cdot 88$ \\
\hline
\end{tabular}

HEI, modified Healthy Eating Index.

*General linear model controlled for student's gender, grade level and neighbourhood distress score.

tReference category.

fLow to high tertile reflecting near to far distance from student's home to supermarket. 
Table 5 HEl scores by school neighbourhood food environmental factors* among grade 7 and 8 students at twenty-one elementary schools, London, Ontario, Canada, 2006-2007

\begin{tabular}{|c|c|c|c|c|c|}
\hline & $\begin{array}{l}\text { No. of } \\
\text { schools }\end{array}$ & $\begin{array}{l}\text { No. of } \\
\text { students }\end{array}$ & $\begin{array}{l}\text { Difference in } \\
\mathrm{HEI} \text { scores }\end{array}$ & SE & $P$ \\
\hline \multicolumn{6}{|c|}{ Distance from school to the nearest convenience store } \\
\hline$<1 \mathrm{~km}$ & 17 & 420 & $0+$ & & \\
\hline$\geq 1 \mathrm{~km}$ & 4 & 160 & $2 \cdot 00$ & 1.00 & 0.049 \\
\hline \multicolumn{6}{|c|}{ Distance from school to the nearest fast-food outlet } \\
\hline$<1 \mathrm{~km}$ & 16 & 407 & $0+$ & & \\
\hline$\geq 1 \mathrm{~km}$ & 5 & 179 & $2 \cdot 60$ & 0.98 & 0.01 \\
\hline \multicolumn{6}{|c|}{ Number of fast-food outlets within $1 \mathrm{~km}$ buffer surrounding school } \\
\hline 0 & 5 & 179 & $2 \cdot 75$ & $1 \cdot 06$ & 0.02 \\
\hline $1-2$ & 4 & 104 & $0 \cdot 66$ & $1 \cdot 14$ & 0.57 \\
\hline$\geq 3$ & c & 297 & $0+$ & & \\
\hline
\end{tabular}

HEI, modified Healthy Eating Index.

*General linear mixed model controlled for student's gender, grade level and neighbourhood distress scores.

tReference category.

\section{Discussion}

The current study highlights the impact of the home and school neighbourhood food environments on adolescents' eating behaviours. A close proximity to convenience stores from an adolescent's home was associated with a low diet quality score. Similarly, a close proximity to convenience stores and fast-food outlets and a high density of fast-food outlets in the neighbourhood surrounding an adolescent's school were also associated with poor nutritional intake. Interestingly, the distance from home to the nearest supermarket was not associated with diet quality scores among the adolescents in our study. Despite the relatively weak dietary measures in the current study, our findings suggest that this is an important area that merits further research employing more rigorous dietary assessment methods.

The influence of unhealthy food opportunities surrounding adolescents' homes and schools on their diet quality may be explained by their food purchasing behaviours. Specifically, using data from our research team's larger project, we found that the closer adolescents lived to fast-food outlets and convenience stores, the more likely they were to purchase food from these outlets when a parent or guardian was not around ${ }^{(31)}$. Not only was distance to the closest food venue important, but the density of these venues was also important; the greater the density of fast-food outlets in the neighbourhood surrounding their home or school, the more likely adolescents were to purchase fast food when a parent or guardian was not around ${ }^{(31)}$.

Given the negative impact of the close proximity of unhealthy food establishments on adolescents' eating behaviours, environmental strategies are vital to help combat the increasing obesity epidemic. In the current study, approximately $80 \%$ of schools and over $50 \%$ of participants' homes were located within walking distance to fast-food outlets and convenience stores. This is consistent with findings from a recent study in New Zealand where food environments surrounding schools were characterized by a high density of fast-food outlets and convenience stores, particularly in more socially deprived settings ${ }^{(44)}$. As underscored by Simon et al. (p. 288) ${ }^{(20)}$ :

[w]hile strategies to curb the childhood obesity epidemic must include more effective education of children and their parents on nutrition and portion control, these efforts will likely fall far short without concurrent environmental change efforts that tip the balance in favor of healthier food purchases.

Therefore, it follows that possible policy and environmental interventions include regulating the density of fast-food restaurants in certain neighbourhoods, offering economic incentives for establishments that offer affordable fresh produce and for restaurants that offer healthier food options and smaller portions ${ }^{(20)}$.

Supermarket availability and proximity has been identified as influencing eating behaviours in adult populations. A recent national-level data analysis based on the Behavioral Risk Factor Surveillance System in the USA showed that the odds of consuming fruits and/or vegetables five times or more daily decreased as distance to supermarkets increased in metropolitan areas, but not in non-metropolitan areas ${ }^{(45)}$. Moore et al. also found that adults with no supermarkets near their homes were less likely to have a healthy diet than those with the most ${ }^{(46)}$. However, Pearce et al. did not observe any association between access to supermarkets or convenience stores and fruit or vegetable consumption among New Zealand adults ${ }^{(47)}$. Similarly, we found no association between supermarket proximity and dietary quality in our adolescent participants. The adolescents in the current study may have perceived supermarkets as a place for adults/parents to purchase larger-scale groceries, rather than a place for adolescents to buy a snack.

\section{Limitations}

Although the present study highlights important findings about the relationship between adolescents' home and school environments and their dietary intake, the study is not without limitations. First, the study used a cross-sectional 
design; thus, the association between the neighbourhood food environment and adolescents' eating behaviours cannot be considered a causal relationship. Second, our sample included a purposeful selection of schools from varying and diverse geographical areas within the city with respect to socio-economic status, neighbourhood land use and built form. The sample did not comprise a random sample of grade 7 and 8 students from the host city. Nevertheless, the socio-economic profile of the current sample was consistent with the overall profile of the City of London populations ${ }^{(48)}$, which may somewhat lessen the limitation of research finding generalizability. Third, although the Block Kids 2004 FFQ was a practical tool for use in the current study, a number of weaknesses were associated with this technique. For instance, the tool was found to be less accurate for children below the age of 11 years; although this was not a major concern for our study as $99 \%$ of our participants were 12 years and older $^{(49)}$. The relatively low usable rate $(77 \%)$ of dietary data was another limitation. The NutritionQuest system flags implausible dietary data when a questionnaire exhibits signs of playfulness or partial completion. The study by Hovland et al. using the same instrument among 3rd graders also reported a usable rate of $74 \%{ }^{(50)}$. It was suggested that one-on-one administration of the Block Kids 2004 FFQ may increase usable dietary data rate. Furthermore, the Block Kids 2004 FFQ was found to be less accurate in assessing food groups ${ }^{(49)}$, which may somewhat compromise the validity of the HEI. In addition, the dietary data outputs by the NutritionQuest system were based on the American MyFood Pyramid food group servings, which make it difficult to calculate the HEIC-2009, a healthy eating index for Canadian children $^{(51)}$. Because the main purpose of our study was to determine the association of eating behaviours and environmental factors, rather than to describe eating behaviours of Canadian children, the application of this American-based healthy eating index (i.e. HEI-2005) is less likely to compromise the validity of the epidemiological associations. Finally, the current study reported a somewhat lower energy intake than previously reported for Canadian children aged 9-13 years $(10234 \mathrm{~kJ} / \mathrm{d}$ $(2446 \mathrm{kcal} / \mathrm{d})$ for boys and $8514 \mathrm{~kJ} / \mathrm{d}(2035 \mathrm{kcal} / \mathrm{d})$ for girls) based on data from the Canadian Community Health Survey (CCHS) $2 \cdot 2^{(52)}$. Our results, however, were similar to those for grade 6-8 students in Ontario by Hanning et al., where energy intake was $7690 \mathrm{~kJ} / \mathrm{d}$ $(1838 \mathrm{kcal} / \mathrm{d})$ in boys and $6309 \mathrm{~kJ} / \mathrm{d}(1508 \mathrm{kcal} / \mathrm{d})$ in girls $^{(53)}$. The differences in energy intake among these studies may be due the application of different dietary assessment methodology. For instance, a $24 \mathrm{~h}$ dietary recall was used in CCHS $2 \cdot 2^{(52)}$, while a $24 \mathrm{~h}$ web-based instrument was used in Hanning et al.'s study ${ }^{(53)}$. Nevertheless, the primary purpose of the present study was to determine the association of food environment and diet quality, not to describe the actual dietary intake.

\section{Conclusions}

The present study reveals that close proximity to convenience stores in adolescents' home neighbourhoods is associated with low diet quality scores. Within adolescents' school surroundings, close proximity to convenience stores and fast-food outlets and high density of fast-food outlets are associated with low diet quality scores. The implications of these findings highlight the importance of adolescents' home and school neighbourhoods in providing opportunities for unhealthy food choices.

\section{Acknowledgements}

Sources of funding: Support for the present study was provided by the Canadian Institutes of Health Research (CIHR). Conflict of interest: There are no conflicts of interest pertaining to the research. Author contributions: The study was conducted while M.H. was Associate Professor at Brescia University College, London, Ontario and Nutrition Researcher/Educator at the Public Health Research, Education and Development Program, Middlesex-London Health Unit, London, Ontario, Canada. All authors were involved with the conceptual creation of the present research project. M.H. was responsible for leading the analysis of all food-related data and writing the first draft of the manuscript. P.T. led school and participant recruitment, collected all data, assisted with data interpretation and was highly involved with editing the manuscript. J.D.I. was also highly involved with data interpretation and reviewing the manuscript. J.G., K.L. and P.H. provided the geographical analysis of the environmental data and reviewed the manuscript. Acknowledgements: The authors are grateful to the many students who participated in the study and the teachers and principals who provided access to their schools and classrooms to collect the data. They would like to thank Natalie Miandro, Stefanie DeRossi, Jessica Tong, Peggy Tso, Cuong Nguyen, Daniel Beemsigne, Kevin VanLierop and Janet Loebach, all of whom assisted with data collection. Special thanks are extended to Leigh Vanderloo for her assistance formatting the manuscript.

\section{References}

1. Campos P, Saguy A, Ernsberger P et al. (2006) The epidemiology of overweight and obesity: public health crisis or moral panic? Int J Epidemiol 35, 55-60.

2. Wyatt SB, Winters KP \& Dubbert PM (2006) Overweight and obesity: prevalence, consequences, and causes of a growing public health problem. Am J Med Sci 331, 166-174.

3. Freedman DS, Khan LK, Serdula MK et al. (2005) The relation of childhood BMI to adult adiposity: the Bogalusa Heart Study. Pediatrics 115, 22-27.

4. Shields M (2006) Overweight and obesity among children and youth. Health Rep 17, 27-42. 
5. Wang Y \& Lobstein T (2006) Worldwide trends in childhood overweight and obesity. Int J Pediatr Obes 1, 11-25.

6. Richter KP, Harris KJ, Paine-Andrews A et al. (2000) Measuring the health environment for physical activity and nutrition among youth: a review of the literature and applications for community initiatives. Prev Med 31, issue 2, S98-S111.

7. Booth KM, Pinkston MM \& Poston WS (2005) Obesity and the built environment. J Am Diet Assoc 105, 5 Suppl. 1, S110-S117.

8. Diez Roux AV (2003) Residential environments and cardiovascular risk. J Urban Health 80, 569-589.

9. Egger G \& Swinburn B (1997) An 'ecological' approach to the obesity pandemic. BMJ 315, 477-480.

10. Hill JO \& Peters JC (1998) Environmental contributions to the obesity epidemic. Science 280, 1371-1374.

11. Nestle M \& Jacobson MF (2000) Halting the obesity epidemic: a public health policy approach. Public Health Rep 115, 12-24.

12. Sallis JF \& Glanz K (2006) The role of built environments in physical activity, eating, and obesity in childhood. Future Child 16, 89-108.

13. Glanz K, Sallis JF, Saelens BE et al. (2005) Healthy nutrition environments: concepts and measures. Am J Health Promot 19, 330-333.

14. Hill JO, Wyatt HR, Reed GW et al. (2003) Obesity and the environment: where do we go from here? Science $\mathbf{2 9 9}$, 853-855.

15. Frank LD, Sallis JF, Conway TL et al. (2006) Many pathways from land use to health: associations between neighborhood walkability and active transportation, body mass index, and air quality. J Am Planning Assoc 72, 75-87.

16. Papas MA, Alberg AJ, Ewing R et al. (2007) The built environment and obesity. Epidemiol Rev 29, 129-143.

17. Block JP, Scribner RA \& DeSalvo KB (2004) Fast food, race/ ethnicity, and income: a geographic analysis. Am J Prev Med 27, 211-217.

18. Morland K, Wing S, Diez RA et al. (2002) Neighborhood characteristics associated with the location of food stores and food service places. Am J Prev Med 22, 23-29.

19. Austin SB, Melly SJ, Sanchez BN et al. (2005) Clustering of fast-food restaurants around schools: a novel application of spatial statistics to the study of food environments. Am J Public Health 95, 1575-1581.

20. Simon PA, Kwan D, Angelescu A et al. (2008) Proximity of fast food restaurants to schools: do neighborhood income and type of school matter? Prev Med 47, 284-288.

21. Nielsen SJ \& Popkin BM (2004) Changes in beverage intake between 1977 and 2001. Am J Prev Med 27, 205-210.

22. Nielsen SJ, Siega-Riz AM \& Popkin BM (2002) Trends in food locations and sources among adolescents and young adults. Prev Med 35, 107-113.

23. Guthrie JF, Lin BH \& Frazao E (2002) Role of food prepared away from home in the American diet, 1977-78 versus 1994-96: changes and consequences. J Nutr Educ Behav 34, 140-150.

24. Lin BH, Guthrie J \& Frazao E (1999) Quality of children's diets at and away from home: 1994-1996. Food Review January-April, 2-10.

25. Timperio A, Ball K, Roberts R et al. (2008) Children's fruit and vegetable intake: associations with the neighbourhood food environment. Prev Med 46, 331-335.

26. Grafova IB (2008) Overweight children: assessing the contribution of the built environment. Prev Med 47, 304-308.

27. Powell LM, Auld MC, Chaloupka FJ et al. (2007) Associations between access to food stores and adolescent body mass index. Am J Prev Med 33, 4 Suppl., S301-S307.
28. Oreskovic NM, Winickoff JP, Kuhlthau KA et al. (2009) Obesity and the built environment among Massachusetts children. Clin Pediatr (Phila) 48, 904-912.

29. Spence JC, Cutumisu N, Edwards J et al. (2009) Relation between local food environments and obesity among adults. BMC Public Health 9, 192-197.

30. Pearce J, Hiscock R, Blakely T et al. (2009) A national study of the association between neighbourhood access to fastfood outlets and the diet and weight of local residents. Health Place 15, 193-197.

31. He M, Tucker P, Gilliland J et al. (2011) The influence of local food environments on adolescents' food purchasing behaviors. Int J Environ Res Public Health (In the Press).

32. Larsen K, Gilliland J, Hess P et al. (2009) The influence of the physical environment and sociodemographic characteristics on children's mode of travel to and from school. Am J Public Health 99, 520-526.

33. Tucker P, Irwin JD, Gilliland J et al. (2009) Environmental influences on physical activity levels in youth. Health Place 15, 357-363.

34. Tucker P, Irwin JD, Gilliland J et al. (2008) Adolescents' perspective of home, school and neighborhood environmental influences on physical activity and dietary behaviors. Children Youth Environ 18, 12-35.

35. Vernon's City Directory (2006) City of London. Hamilton: Vernon Directories Ltd.

36. Cullen KW, Himes JH, Baranowski T et al. (2004) Validity and reliability of a behavior-based food coding system for measuring fruit, $100 \%$ fruit juice, vegetable, and sweetened beverage consumption: results from the Girls Health Enrichment Multisite Studies. Prev Med 38, Suppl., S24-S33.

37. Bow CJ, Waters NM, Faris PD et al. (2004) Accuracy of city postal code coordinates as a proxy for location of residence. Int J Health Geogr 3, 5-13.

38. Larsen K \& Gilliland J (2008) Mapping the evolution of 'food deserts' in a Canadian city: supermarket accessibility in London, Ontario, 1961-2005. Int J Health Geogr 7, 16-31.

39. Britten P, Marcoe K, Yamini S et al. (2006) Development of food intake patterns for the MyPyramid Food Guidance System. J Nutr Educ Behav 38, 6 Suppl., S78-S92.

40. Guenther PM, Reedy J \& Krebs-Smith SM (2008) Development of the Healthy Eating Index-2005. J Am Diet Assoc 108, 1896-1901.

41. Guenther PM, Reedy J, Krebs-Smith SM et al. (2008) Evaluation of the Healthy Eating Index-2005. J Am Diet Assoc 108, 1854-1864.

42. Willett WC (1998) Nutritional Epidemiology, 2nd ed. New York, NY: Oxford University Press.

43. Mason MJ, Cheung I \& Walker L (2004) The social ecology of urban adolescent substance use: a case study utilizing geographic information systems. J Primary Prev 25, 271-282.

44. Day PL \& Pearce J (2011) Obesity-promoting food environments and the spatial clustering of food outlets around schools. Am J Prev Med 40, 113-121.

45. Michimi A \& Wimberly MC (2010) Associations of supermarket accessibility with obesity and fruit and vegetable consumption in the conterminous United States. Int $J$ Health Geogr 9, 49.

46. Moore LV, Diez Roux AV, Nettleton JA et al. (2008) Associations of the local food environment with diet quality - a comparison of assessments based on surveys and geographic information systems: the Multi-ethnic Study of Atherosclerosis. Am J Epidemiol 167, 917-924.

47. Pearce J, Hiscock R, Blakely T et al. (2008) The contextual effects of neighbourhood access to supermarkets and convenience stores on individual fruit and vegetable consumption. J Epidemiol Community Health 62, 198-201.

48. City of London Community Support Services Division (2011) City of London: Selected Demographic Statistics 
from the 2006 Census. http://www.london.ca/About_London/ PDFs/NeighbourhoodworksheetJuly2011cityoflondon.pdf (accessed February 2012).

49. Cullen KW, Watson K \& Zakeri I (2008) Relative reliability and validity of the Block Kids Questionnaire among youth aged 10 to 17 years. J Am Diet Assoc 108, 862-866.

50. Hovland JA, McLeod SM, Duffrin MW et al. (2010) Schoolbased screening of the dietary intakes of third graders in rural Appalachian Ohio. $J$ Sch Health 80, 536-543.
51. Woodruff SJ \& Hanning RM (2010) Development and implications of a revised Canadian Healthy Eating Index (HEIC-2009). Public Health Nutr 13, 820-825.

52. Garriguet D (2007) Canadians' eating habits. Health Rep $\mathbf{1 8}$, $17-32$.

53. Hanning RM, Woodruff SJ, Lambraki I et al. (2007) Nutrient intakes and food consumption patterns among Ontario students in grades six, seven, and eight. Can J Public Health 98, 12-16. 